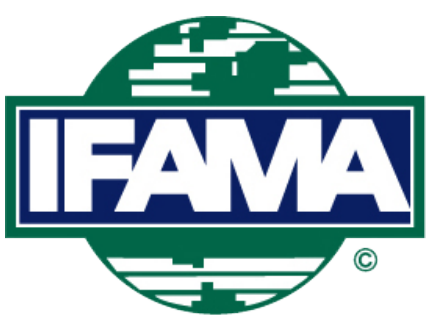

International Food and Agribusiness Management Review

Volume 24, Issue 1, 2021; DOI: 10.22434/IFAMR2020.0119

Received: 28 July / Accepted: 25 September 2020

\title{
Does higher market power necessarily reduce efficiency? Evidence from Chinese rice processing enterprises
}

\section{RESEARCH ARTICLE}

\author{
Jiawu Dai ${ }^{\circledR a}$, Yuchen Feng ${ }^{\mathrm{b}}$, Xiuqing Wang ${ }^{\mathrm{c}}$ and Guang Yuan ${ }^{\mathrm{d}}$ \\ ${ }^{a}$ PhD, ${ }^{b}$ Postgraduate, ${ }^{d}$ Lecturer, Hunan Key Laboratory of Macroeconomic Big Data \\ Mining and its Application, School of Business, Hunan Normal University, No. 36 \\ Lushan Road, Yuelun District, Changsha, Hunan, 410081, China P.R. \\ 'Professor, College of Economics and Management, China Agricultural University, \\ No. 17 Qinghua East Road, Haidian District, Beijing, 100083, China P.R.
}

\begin{abstract}
This study evaluates the market power and cost efficiency of China's rice processing firms through a stochastic frontier cost function. The effect of market power on cost efficiency is tested using the two-stage ordinary least squares method and a Hausman-Taylor type instrumental variable. On average, firms in the industry have weak market power but high cost efficiency, which has been declining since the 2008 global financial crisis. Firms with stronger market power exhibit higher cost efficiency, contradicting the quiet life hypothesis. This effect is more significant for firms with weaker market power after the global financial crisis. The enhancement of market power may help save resources for improving management and efficiency for Chinese rice processing industry.
\end{abstract}

Keywords: market power, cost efficiency, quiet life hypothesis JEL code: L13, Q13

\footnotetext{
(1)Corresponding author: daijiawu@hunnu.edu.cn
} 


\section{Introduction}

Traditional microeconomic theory assumes that all productions are optimised; in other words, under a given level of technology and resources, cost minimisation and profit maximisation can always be achieved. In this context, any economic deviation from optimisation is attributed to random disturbances. However, although producers seek to achieve optimisation, they may be unable to accomplish their goals. Given the input price and other conditions, not all producers can minimise the cost by configuring or adjusting the input of various factors, that is, not all producers are cost efficient (Kumbhakar and Lovell, 2000). Therefore, the means of measuring cost efficiency and identifying its determinants have become central in the field of industrial organisation.

Market power is deemed as one of the crucial determinants of cost efficiency. According to the quiet life hypothesis (QLH) proposed by Hicks (1935), managers and employees in a firm with strong market power tend to be 'lazy' and lose the incentive to maximise profit, as they can easily obtain desirable compensation owing to the firm's market power. In this case, the cost efficiency of the company is generally lower than that of firms operating in a highly competitive market. Therefore, increased market competition may help improve the cost efficiency of those firms. Leibenstein (1966) shows that in the presence of substantial market power, cost inefficiency may lead to a large welfare loss. Comanor and Leibenstein (1969) analyse the welfare losses caused by a monopoly (or market power) and show that focusing on allocative efficiency while neglecting cost efficiency may cause significant bias. The allocative efficiency loss measures the adverse effect of firms' market power on the welfare of the entire industry. This is always ignored by a single firm as long as it can obtain excess profit through its market power. In other words, increasing the market power always benefits a firm regardless of cost efficiency, even though it may cause a net welfare loss to the whole industry. However, if the cost efficiency is taken into consideration, the enhancement of market power may not necessarily benefit all firms. This theoretical conjecture has been demonstrated by various empirical studies (Berger and Hannan, 1998; Delis and Tsionas, 2009; Kutlu and Sickles, 2012).

In contrast, other studies contend that an increase in market power improves firms' cost efficiency. These studies suggest that a certain degree of market power increases the profitability of companies, which are more likely to improve cost efficiency by introducing high-performing management teams. Meanwhile, firms with stronger market power often attract professional talent and strategic capital, which contribute to improving cost efficiency (Chandy and Tellis, 2000). Some scholars contend that firms should grow 'bigger and stronger' through industrial policies such as subsidies, credit support, and mergers and acquisitions, especially in developing countries such as China.

Testing the effect of market power on cost efficiency is of great academic and policy significance, particularly in the context of China's rice processing industry. Rice is one of the fundamental rations in China. Its production and sales significantly contribute to the country's food security (Chen et al., 2020). At the same time, optimising the market structure and improving the cost efficiency of the rice processing industry are key tasks of the supply-side structural reform proposed by the current supremo of the country. In the case of China's rice processing industry, the QLH predicts that excessive market power will not only lead to allocative efficiency loss but also reduce the cost efficiency of firms. Hence, rationally regulating the monopolistic behaviour of firms is necessary for improving their cost efficiency. An alternative approach would imply strengthening firms' market power through subsidies and industrial policies.

Although the QLH has been tested in various manners, previous studies mainly focused on the banking sector and did not address the potential endogeneity of market power. Using firm-level panel data from 1999 to 2011, this study evaluates the market power and cost efficiency of China's rice processing firms through a stochastic frontier cost function. The effect of market power on cost efficiency is also tested using the two-stage least squares (2SLS) method and a Hausman-Taylor type instrumental variable (IV). The contribution of this study is twofold. First, to the best of the authors' knowledge, this is the first study testing the QLH for China's rice processing industry using firm-level data. The empirical results provide 
new insights into the market structure and performance of China's rice processing sector. The results also shed light on the heterogeneous impact of market power on cost efficiency in terms of period, firm-scale level, and competition intensity. From a methodological perspective, this study proposes a new HausmanTaylor type instrument to address the endogeneity of market power, which has severely affected previous empirical research on the QLH.

The empirical results show that, on average, firms in the industry have very weak market power but relatively high cost efficiency, which has been declining since the 2008 financial crisis. The study also finds that firms with stronger market power tend to exhibit higher levels of cost efficiency, which contradicts the QLH. This effect is more pronounced for firms with weaker market power after 2008. Therefore, intensifying the market power of rice processing firms may improve their cost efficiency.

\section{Literature review}

Since Hicks (1935) proposed the QLH, the relationship between market power and cost efficiency has been extensively discussed. The existing research can be divided into two streams.

The first stream supports the QLH, contending that market power has a negative impact on firms' cost efficiency. For example, Berger and Hannan (1998) verified the QLH for the US banking sector. They found that banks with strong market power may obtain excess benefits with less input due to their monopoly. Hence, their managers may lack the motivation to reduce costs as much as possible. In addition, driven by market power, managers may set and achieve specific development goals instead of minimising costs, thus reducing cost efficiency. Delis and Tsionas (2009) addressed the European Monetary Union and the US banking sector. They found a negative correlation between market power and cost efficiency, in line with the QLH. Kutlu and Sickles (2012) also proved the existence of a 'quiet life' phenomenon in the US aviation industry. To address the endogeneity of market power, the authors used the lagged Lerner index as an instrument. The 2SLS estimation results supported the QLH, especially for subsamples in which the Lerner index was below the median. In addition, the QLH has also been proven for banks in various regions and countries such as Taiwan (Tu and Chen, 2000), Germany (Koetter and Vins, 2008), Europe and the United States (Delis and Tsionas, 2009; Schaeck and Cihak, 2008), Italy (Coccorese and Pellecchia, 2010), and Japan (Tetsushi et al., 2012).

The second stream of literature found a positive correlation between market power and cost efficiency, strongly rejecting the QLH. For example, Maudos and Fernández de Guevara (2007) conducted a study on the European banking industry and found evidence that openly contradicts the QLH. Based on the stochastic frontier cost function, Solis and Maudos (2008) measured market power and cost efficiency, and tested the QLH for the Mexican banking system using micro data at bank level. Their results significantly rejected the QLH for Mexican banks, which meant, on average, banks with strong market power tended to have a high level of cost efficiency in the deposit market. Huang et al. (2018) addressed the banking industries in five European countries (Bulgaria, Latvia, Czech Republic, Poland, and Russia) by using stochastic frontier methods and micro-panel data and found a significant and positive correlation between market power and cost efficiency. Similar results have also been obtained by other studies on the banking industry in various countries and regions such as Europe (Casu and Girardone, 2009), the United States (Koetter et al., 2012), the Czech Republic (Pruteanu-Podpiera et al., 2008), Jordan (Al-Jarrah and Gharaibeh, 2009), the Arabian Gulf (Al-Muharrami and Mathews, 2009), and China (Fu and Heffernan, 2009).

To the best of the authors' knowledge, most previous studies focused on the banking sector, and very little attention has been paid to manufacturing or processing industries. In addition, earlier studies on the QLH measured market power using the market concentration or market share indicators (Shepherd, 1972) and should not be directly used as a measure of competitiveness (Claassen and Laeven, 2004, 2005; Maudos and Fernández de Guevara, 2007). In addition, the endogeneity of market power still represents a challenge for estimation. The source of endogeneity may be twofold. On the one hand, reciprocal causality may exist 
between market power and cost efficiency. On the other hand, omitted variable bias may be observed, as the unobservable factors affecting cost efficiency may be correlated with market power. Thus, the ordinary least squares (OLS) estimation would likely generate inconsistent results. The best strategy to address the potential endogeneity of market power seems to be the 2SLS method, using an adequate instrument, as discussed in Section 4.

\section{Materials and methods}

\subsection{Measuring market power and cost efficiency}

As a first step, the value of market power was estimated for each observation. ${ }^{1}$ Traditional estimation methods, including the new empirical industrial organisation model, the Solow Residual approach, and the nonparametric method, can only estimate an average Lerner index at the industry level, which is an inappropriate dependent variable for the scope of this study.

Recent research suggests that a more feasible solution is to calculate the Lerner index by estimating a cost function and then calculating the marginal cost as well as the Lerner index. The stochastic frontier cost function is the most advanced and widely used setting for estimating a cost function since it best fits costs and generates relatively consistent estimates (Bauer et al., 1997; Solís and Maudos, 2008). Based on the stochastic frontier production function proposed by Aigner et al. (1977) and Meeusen and Van den Broeck (1977), Schmidt and Lovell (1979) constructed a dual stochastic frontier cost function, which has been extensively used to estimate cost efficiency. For instance, Berger and Hannan (1998), Maudos and Fernández de Guevara (2007), and Solís and Maudos (2008) used this approach to test the QLH for the banking industry in the United States, the EU-15, and Mexico.

First, firm $i$ 's stochastic cost frontier is assumed as:

$$
C_{i}=C\left(y_{i}, \omega_{i}, u_{i}, v_{i}\right)
$$

Assuming that the efficiency and random error terms are multiplicative, the logarithmic transformation of the above equation can be obtained as:

$$
\ln c_{i}=f\left(y_{i}, \omega_{i}\right)+\ln u_{\mathrm{i}}+\ln v_{\mathrm{i}}
$$

where $c_{i}$ and $y_{i}$ are the total cost and output of firm $i$, respectively, $\omega_{i}$ is a vector of factor prices, and $u_{\mathrm{i}}$ represents cost inefficiency, which is assumed to have a semi-normal distribution, $u \sim N\left(0, \sigma^{2}{ }_{u}\right) ; v$ is a white noise term subject to a bilateral normal distribution (Two-side Normal), $v \sim$ i.i.d. $N\left(0, \sigma^{2}{ }_{v}\right)$.

The cost efficiency of firm $i$ is defined as the ratio of the industry's minimum cost to the real cost of the firm:

$$
E_{i}^{c}=\frac{c_{\min }}{c_{i}}=\frac{\exp \left(f\left(y_{i}, \omega_{i}\right)\right) \exp \left(\ln v_{i}\right)}{\exp \left(f\left(y_{i}, \omega_{i}\right)\right) \exp \left(\ln u_{i}\right) \exp \left(\operatorname{lnv} v_{i}\right)}=\exp \left(-\ln u_{i}\right) .
$$

$C_{\text {min }}$ represents the smallest average cost of all firms in a certain year, ${ }^{2}$ and its ratio to $C_{i}$ is used to measure the difference between the lowest cost of firm $i$ and that of the whole industry. This term represents the cost efficiency of firm $i$. Since the cost is positive, the value range of $E^{c}{ }_{i}$ is $(0,1)$; a value of 1 means that optimal cost efficiency is achieved.

\footnotetext{
${ }^{1}$ Market power refers to the ability of a firm to make excessive profit through raising product prices above its marginal cost (Raper et al., 2007; Solis and Maudos, 2008). There have been several indicators for proxying market power since the 1930s, and the most popular one is the Lerner index developed by Abba Lerner (1934). One of the most important advantages of the Lerner index is its ability to measure directly the markup ratio of product price and marginal cost. Therefore, it has been widely applied in much of the literature until recently (for example Casarin et al., 2020; Chen and Yu, 2019; Vives, 2020, etc.).

${ }^{2}$ We use the average cost instead of gross cost since the latter almost entirely depends on the firm's output level, thus, only marginally related to market power.
} 
According to Jondrow et al. (1982) and Solís and Maudos (2008), $u_{i}$, which represents inefficiency, can be estimated as the conditional expectation of the error term:

$$
E\left(u_{i} \mid \varepsilon_{i}\right)=\frac{\sigma \lambda}{1+\lambda^{2}}\left[\frac{\phi\left(\varepsilon_{i} \lambda / \sigma\right)}{\Phi\left(-\varepsilon_{i} \lambda / \sigma\right)}-\frac{\varepsilon_{i} \lambda}{\sigma}\right],
$$

where $\sigma^{2}=\sigma_{u}^{2}+\sigma_{v}^{2}$ is the total variance, $\lambda=\sigma_{u} / \sigma_{v}$ and $\phi(\cdot)$ and $\Phi(\cdot)$ are the density function and cumulative density function of the standard normal distribution, respectively.

In line with the unique situation of China's food industry, this study constructs a random boundary cost function, as follows:

$$
\begin{gathered}
\ln c_{i t}=\sum \gamma_{h} \ln \omega_{h i t}+\gamma_{q} \ln q_{i t}+\frac{1}{2} \sum \sum \gamma_{h j} \ln \omega_{h i t} \ln \omega_{j i t}+\frac{1}{2} \gamma_{q q}\left(\ln q_{i t}\right)^{2}+ \\
\sum \gamma_{h q} \ln \omega_{h i t} \ln q_{j i t}+\rho_{t} T+\rho_{q} T \ln q_{i t}+\sum \rho_{h} T \ln \omega_{h i t}+\ln u_{i}+\ln v_{i},
\end{gathered}
$$

where $c_{i t}$ and $q_{i t}$ are the total cost and total output of firm $i$, respectively, $\omega_{i t}$ is the factor price of the firm (including raw materials, labour, and capital), and $T$ is the time trend, which represents technological progress. By taking the derivative with respect to $q_{i t}$ on both sides of Equation 5, the formula for calculating the marginal cost is obtained as follows:

$$
m c_{i t}=\left(\gamma_{q}+\gamma_{q q} \ln q_{i t}+\sum \gamma_{h q} \ln \omega_{h i t}+\rho_{q} T\right) \frac{c_{i t}}{q_{i t}} .
$$

Thus, the Lerner index $\left(L_{i t}=\left(p_{i t}-m c_{i t}\right) / p_{i t}\right)$ of the firm can be further estimated.

\subsection{The quiet life hypothesis}

To further test whether the QLH holds in China's rice processing industry, this study follows Solís and Maudos (2008) to construct the econometric model as follows:

$$
E_{i t}^{c}=\alpha+\beta_{1} L_{i t}+\sum_{k=1}^{5} \gamma_{k} X_{i t}^{k}+\gamma_{t}+\mu_{i}+\delta_{i t}+\varepsilon_{i t},
$$

where $E^{c}{ }_{i}$ and $L_{i t}$ are the cost efficiency and the Lerner index, respectively, $X_{i t}$ is a vector of control variables that includes the logarithm of the total assets $\left(\ln T A_{i t}\right)$ for firm $i$ in year $t$, the capital input/output ratio, and the labour input/output ratio, which control for the impact of firm size and factor input preferences on firm cost efficiency, respectively; $\gamma t$ represents the time fixed effect, which controls for the effect of unobservable factors on cost efficiency, such as the economic situation, institutional environment, and macro policies; $\mu_{i}$ represents the individual fixed effect, which is used to control for each firm's time-invariant and unobservable effects, such as the firm's geographical location and management ability; $\delta_{i t}$ represents the year-by-firm fixed effect, which controls for each firm's time-variant and unobservable effects, such as accumulated managerial experience and development trend.

\subsection{Data description}

This study employed panel data of Chinese rice processing companies observed from 1999 to 2011. The data were obtained from several databases including the Annual Survey of Industrial Firms, China Statistical Yearbook, China Agricultural Product Price Survey Yearbook, and National Agricultural Product CostRevenue Data Collection, among others. The final dataset includes both state-owned and non-state-owned companies above the designated size (with production value more than CNY 5 billion). ${ }^{3}$ Observations that were available for less than three consecutive years and outliers (such as negative or 0 values) were discarded.

\footnotetext{
${ }^{3}$ The firm-level data used in our study was acquired directly from the most widely used micro-data source in China, the 'Annual Survey of Industrial Firms' (https://microdata.stats.gov.cn), maintained by the National Bureau of Statistics of China (see Brandt et al. (2017), Che and Zhang (2017), and Brandt et al. (2012) etc. for detailed descriptions for this dataset). The Bureau only collects and releases data for firms with production value of more than CNY 5 billion, namely the so-called above-designated-size firms.
} 
The measurement unit of output and raw material input is tonne, while the price of products and raw material is expressed in $1000 \mathrm{CNY} /$ tonne. The annual mean balance of fixed asset-net value is expressed in 1000 $\mathrm{CNY}^{4}$ and the number of employees and wage rates are measured in terms of person and $1000 \mathrm{CNY} /$ worker per year, respectively. All the price-related variables are deflated by the Producer's Price Index. The mean of the primary variables in each industry and the sample size are reported in Table 1.

The statistical summary results reported in Table 1 show that the average annual production scale of rice processing firms is about 17,700 tonnes, the average annual mean balance of fixed asset-net value is CNY 6.041 million, and the average number of employees is 66, indicating that the average size of the companies is rather small. The standard deviations of these scale variables are large, and the extreme difference (the difference between the maximum and the minimum values) is large and significant, indicating substantial differences within the sector.

\section{Results}

\subsection{Estimation of market power and cost efficiency}

After obtaining the coefficients from Model 5, the Lerner index of rice processing firms is measured using Equation 6. The statistical summary is shown in Table 2. The number of rice processing firms in China first increases and then decreases during the sample period. The turning point is the 2008 global financial crisis. The Lerner index is positive every year, except for the negative value in 1999. A negative value of the Lerner index indicates that the firm experiences a short-term loss. If the situation will be reversed in the long run, then the firm will likely survive. Conversely, in the presence of a long-term loss, the firm will be weeded out from the market.

From 1999 to 2011, the average Lerner index of rice processing firms in China is relatively small, always less than 0.1 , indicating intense competition in the sector. The possible explanation is twofold. On the one hand, the degree of product differentiation of rice is very small, and the barriers to entry of the industry are low. On the other hand, China's rice production has increased over time, which induced oversupply and increased competition in the industry. In 2014, 19 state-owned firms suffered losses, accounting for 19\% of all state-owned enterprises in the industry. Meanwhile, the number of loss-making private firms in the industry was 89 , indicating an increase of $25.4 \%$ over the previous year (Liu, 2017).

Table 1. Statistical summary of key variables. ${ }^{1}$

\begin{tabular}{llrrrr}
\hline Variables & Obs. & \multicolumn{1}{c}{ Mean } & Std. Dev. & Min. & \multicolumn{1}{c}{ Max. } \\
\hline Output & 5,526 & 17,700 & 39,100 & 6.346 & 661,000 \\
Output price & 5,526 & 2.707 & 0.663 & 1.406 & 5.057 \\
Net value of fixed assets & 5,526 & $6,040.720$ & 24,900 & 6.842 & 747,000 \\
Medium and long-term loan interest rate & 5,526 & 0.063 & 0.006 & 0.055 & 0.071 \\
Employees & 5,526 & 66 & 126 & 1 & 2,330 \\
Wage rates & 5,526 & 18.651 & 7.070 & 6.347 & 57.633 \\
Paddy input & 5,526 & 24,300 & 53.500 & 8.694 & 906,000 \\
Paddy price & 5,526 & 1.641 & 0.414 & 0.853 & 2.868 \\
Total cost & 5,526 & 46,000 & 101,000 & 10.131 & $1,730,000$ \\
\hline
\end{tabular}

${ }^{1}$ All the value variables are deflated by the Producer Price Index collected from the China Statistical Yearbook (National Bureau of Statistics of China, 2012).

\footnotetext{
${ }^{4}$ The capital used in our study is the annual mean balance of fixed asset-net value, which is taken from the 'Annual Survey of Industrial Firms' directly.
} According to Chinese accounting standards, this variable is calculated by subtracting the depreciation value from the original value of fixed assets. 
Table 2. Estimation results of Lerner index.

\begin{tabular}{lcclll}
\hline Year & Obs. & Mean & Std. Dev. & Min. & Max. \\
\hline 1999 & 99 & -0.002 & 0.128 & -0.701 & 0.250 \\
2000 & 119 & 0.014 & 0.072 & -0.390 & 0.189 \\
2001 & 194 & 0.005 & 0.104 & -0.616 & 0.148 \\
2002 & 185 & 0.015 & 0.114 & -1.002 & 0.139 \\
2003 & 218 & 0.020 & 0.078 & -0.701 & 0.146 \\
2004 & 434 & 0.025 & 0.047 & -0.263 & 0.241 \\
2005 & 590 & 0.024 & 0.050 & -0.337 & 0.284 \\
2006 & 730 & 0.021 & 0.060 & -0.721 & 0.587 \\
2007 & 805 & 0.028 & 0.052 & -0.329 & 0.374 \\
2008 & 609 & 0.042 & 0.057 & -0.115 & 0.374 \\
2009 & 525 & 0.041 & 0.052 & -0.189 & 0.296 \\
2010 & 517 & 0.009 & 0.052 & -0.303 & 0.303 \\
2011 & 501 & 0.029 & 0.148 & -0.415 & 0.894 \\
\hline
\end{tabular}

The results reported in Table 3 show that the cost efficiency of rice processing firms in China is relatively high overall, and the mean value is approximately 0.9 ; but some firms with low cost efficiency are observed, and the lowest value is below 0.7 in some years. The possible reason to explain the high level of cost efficiency may be that Chinese rice processing firms are generally characterised by small size, low profit rate, and fierce competition, so they have to control their costs strictly. Based on survey data from rice processing firms in Jiangsu province in 2017, Wang et al. (2019) also found a high degree of efficiency (the mean value is 0.87 ), which is very close to the mean of our estimation in 2011. However, since 2005, the average cost efficiency of Chinese firms has shown a continuous downward trend, reaching the lowest point, 0.855 , in 2011. The decreasing trend of cost efficiency from 2005 might be closely related to the government's tremendous emphasis on food security since the early 2000s, which encouraged a rapid expansion of rice production, but which also neglected cost control. Therefore, policies led to increased resource waste and decreased cost efficiency (Yu, 2019). Based on the SFA approach, Yu et al. (2019) and Liu (2019) also found a decreasing trend of cost efficiency for China's wheat and rice production, respectively. The increase in the production cost of rice at farm gate would be passed on to the downstream processing industry, and thus result in decreased cost efficiency for rice processing firms. Another possible reason for the decrease is that the Chinese government increased subsidies for agribusiness since the beginning of the 2000s, which would induce rent-seeking behaviour and cost inefficiency (Dai and Li, 2020b).

The current development of the rice processing industry is not smooth. Improving the profitability and operating efficiency of rice processing firms through structural optimisation and other methods is central for China's current and future 'three rural' policies.

\subsection{The impact of market power on cost efficiency}

First, this study estimates Model 7 using the OLS method and adds control variables and fixed effects step by step. As shown in Table 4, the impact of market power on cost efficiency is positive in all settings. Even if we control for the year and firm fixed effects simultaneously, the coefficient on market power still keeps unchanged in both sign and statistical significance. In Model 5, which controls for the interaction term between the year and firm effects, the coefficient on market power is 0.173 , and statistically significant at the $1 \%$ level. We set this as the benchmark model. 
Table 3. Estimation results of cost efficiency.

\begin{tabular}{lcllll}
\hline Year & Obs. & Mean & Std. Dev. & Min. & Max. \\
\hline 1999 & 99 & 0.969 & 0.032 & 0.819 & 0.998 \\
2000 & 119 & 0.960 & 0.041 & 0.752 & 0.997 \\
2001 & 194 & 0.954 & 0.048 & 0.666 & 0.998 \\
2002 & 185 & 0.954 & 0.046 & 0.717 & 0.999 \\
2003 & 218 & 0.957 & 0.043 & 0.717 & 0.999 \\
2004 & 434 & 0.971 & 0.022 & 0.795 & 1.037 \\
2005 & 590 & 0.962 & 0.028 & 0.721 & 1.053 \\
2006 & 730 & 0.952 & 0.035 & 0.627 & 0.999 \\
2007 & 804 & 0.943 & 0.037 & 0.621 & 1.017 \\
2008 & 608 & 0.941 & 0.028 & 0.801 & 0.997 \\
2009 & 524 & 0.925 & 0.030 & 0.814 & 1.045 \\
2010 & 516 & 0.896 & 0.040 & 0.745 & 0.995 \\
2011 & 500 & 0.855 & 0.054 & 0.658 & 0.993 \\
\hline
\end{tabular}

Table 4. The effect of market power on cost efficiency with the ordinary least square method. ${ }^{1}$

\begin{tabular}{llllll}
\hline & $\mathbf{1}$ & $\mathbf{2}$ & $\mathbf{3}$ & $\mathbf{4}$ & $\mathbf{5}$ \\
\hline Lerner index & $0.160^{* * *}$ & $0.170^{* * *}$ & $0.168^{* * *}$ & $0.021^{* *}$ & $0.173^{* * *}$ \\
& $(0.012)$ & $(0.014)$ & $(0.015)$ & $(0.010)$ & $(0.015)$ \\
Log (total asset) & & -0.000 & $0.002^{* * *}$ & $0.002^{* * *}$ & $0.002^{* * *}$ \\
& & $(0.000)$ & $(0.000)$ & $(0.000)$ & $(0.000)$ \\
Capital / output ratio & & $-0.001^{* * *}$ & $-0.001^{* * *}$ & -0.000 & $-0.001^{* * *}$ \\
& & $(0.000)$ & $(0.000)$ & $(0.000)$ & $(0.000)$ \\
Labour / output ratio & & 11.707 & 10.330 & 5.708 & 8.106 \\
& & $(10.653)$ & $(11.762)$ & $(3.606)$ & $(12.624)$ \\
Year fixed effect & no & no & yes & yes & no \\
Firm fixed effect & no & no & no & yes & no \\
Year by firm effect & no & no & no & no & yes \\
Constant & $0.940^{* * *}$ & $0.953^{* * *}$ & $0.944^{* * *}$ & $0.999^{* * *}$ & $0.934^{* * *}$ \\
& $(0.001)$ & $(0.007)$ & $(0.007)$ & $(0.008)$ & $(0.006)$ \\
Obs. & 5,521 & 5,021 & 5,021 & 5,021 & 5,021 \\
$\mathrm{R}^{2}$ & 0.081 & 0.090 & 0.276 & 0.778 & 0.222 \\
\hline${ }^{1}$ Heteroskedasticity-robust standard errors are reported in parentheses below the corresponding coefficients; ${ }^{* *}$ and ${ }^{* * *}$ are significant \\
at the 5 and 1\% levels, respectively.
\end{tabular}

The main concern for the OLS result may be the endogeneity of market power. There may be reciprocal causality between market power and cost efficiency, and correlation may be observed between missing explanatory variables and market power. To address this issue, this study employs the Hausman test for endogeneity. The corresponding chi-square value is 57.69 , which significantly rejects the null hypothesis of exogeneity at the $1 \%$ level, confirming the endogeneity of market power; hence, the OLS estimation result is inconsistent. Therefore, IVs are used to overcome the endogeneity bias.

This study follows Ariss (2010), Koetter et al. (2012), Harding and Lamarche (2014), and Dai and Li (2020a) to construct a firm-specific Hausman-Taylor instrument, which is measured as the annual mean value of the Lerner index for all the firms except firm $i$. This instrument is closely related to firm $i$ 's Lerner index since all firms compete with each other in the same market. However, the average market power of other firms does not directly affect the cost efficiency of firm $i$. Hence, the proposed instrument generates an indirect 
influence on firm $i$ 's cost efficiency through its effect on firm $i$ 's market power. Thus, the Hausman-Taylor type instrument meets the requirements of relevance and exogeneity. Model 7 is estimated using the 2SLS estimation method and the proposed instrument. The results are summarised in Table 5 (for the results of first-stage regressions, see Supplementary Table S1). Column 1 of Table 5 reports the result obtained without controlling for any fixed effect. The estimated coefficient on the Lerner index is 0.526 , which is statistically significant at the $1 \%$ level, indicating that the increase in market power improves firms' cost efficiency. After controlling for the year fixed effect or year-by-firm effects, the coefficients decrease to approximately 0.2 , but they are still significant at the $1 \%$ level. In line with the OLS estimation, the IV regression results strongly reject the QLH. The significant relationship between market power and cost efficiency depends on the fierce competition and dispersed production capacity in China's rice processing industry, as the market power of most firms is small or even negative. In that case, increasing firms' size and market power is conducive to formation of a scale economy, and thus to minimising production costs and to increasing cost efficiency. Our findings are consistent with those of Maudos and Fernández de Guevara (2007), Koetter et al. (2012) and Huang et al. (2018).

Applying an invalid instrument may cause inconsistent estimation results and large variance in the coefficients. Several tests are conducted to ensure the validity of the proposed instrument. First, as shown in columns 1 to 3 of Table 5, the Kleibergen-Paap rk LM statistics are very large, with the corresponding probability values close to 0 , thus strongly rejecting the null hypothesis of under-identification. Second, both the CraggDonald Wald F statistic and the Kleibergen-Paap rk Wald F statistic are larger than the critical value at the $5 \%$ significance level, also rejecting the weak instrument null hypothesis. ${ }^{5}$ These post-estimation tests prove that the instrument used in this study is valid and adequate.

Table 5. The effect of market power on cost efficiency with the two-stage least squares (2SLS) method. ${ }^{1}$

\begin{tabular}{llll}
\hline & $\mathbf{( 1 )}$ & $\mathbf{( 2 )}$ & $\mathbf{( 3 )}$ \\
& $\mathbf{2 S L S}$ & $\mathbf{2 S L S}$ & $\mathbf{2 S L S}$ \\
\hline Lerner index & $0.526^{* * *}$ & $0.191^{* * *}$ & $0.203^{* * *}$ \\
& $(0.070)$ & $(0.026)$ & $(0.050)$ \\
Log (total asset) & $0.004^{* * *}$ & $0.002^{* * *}$ & $0.003^{* * *}$ \\
& $(0.001)$ & $(0.001)$ & $(0.001)$ \\
Capital / output ratio & $-0.001^{* *}$ & $-0.001^{* * *}$ & $-0.001^{* * *}$ \\
& $(0.000)$ & $(0.000)$ & $(0.000)$ \\
Labour / output ratio & 26.709 & 11.094 & 9.350 \\
& $(9.234)$ & $(12.066)$ & $(12.690)$ \\
Year fixed effect & no & yes & no \\
Year by firm effect & no & no & yes \\
Constant & $0.874^{* * *}$ & $0.940^{* * *}$ & $0.928^{* * *}$ \\
& $(0.021)$ & $(0.012)$ & $(0.016)$ \\
Kleibergen-Paap rk LM statistic $[P$-value $]$ & $76.697[0.000]$ & $45.083[0.000]$ & $72.732[0.000]$ \\
Kleibergen-Paap rk Wald F statistic & 88.235 & 140.848 & 85.365 \\
Cragg-Donald Wald F statistic & 144.831 & $7,581.586$ & 161.464 \\
Obs. & 5,021 & 5,021 & 5,021 \\
$\mathrm{R}^{2}$ & - & 0.274 & 0.220 \\
\hline${ }^{1}$ Heteroskedasticity-robust standard errors are reported in the parentheses below the corresponding coefficients; ${ }^{* *}$ and & \\
significance at the 5 and 1\% levels, respectively. & & &
\end{tabular}

\footnotetext{
${ }^{5}$ The Cragg-Donald Wald F statistic and the Kleibergen-Paap rk Wald F statistic are used to test the weak instrument hypotheses under the assumptions of independently identically distribution (i.i.d.) and non-i.i.d. disturbance term, respectively.
} 


\section{Robustness check and heterogeneity analysis}

To guarantee the reliability of the empirical results, this study conducts various robustness checks. First, two alternative estimation techniques are used, the finite information maximum likelihood (LIML) and the generalised moment estimation (GMM) methods, to estimate the proposed model. These two methods are more robust under weak instrument and heteroscedasticity conditions. As shown in columns 1 and 2 of Table 6, the results estimated by the LIML and GMM methods confirm the results of the 2SLS estimation in columns 2 and 3 of Table 5, which supports the robustness of the findings.

Second, there are two popular assumptions on the distribution of inefficiency terms of stochastic frontier function, namely the half-normal distribution applied in our study, and the exponential distributions (Kumbhakar et al., 2015). In order to further check the robustness of our findings, we estimate the stochastic frontier cost function by assuming an exponential distribution of the inefficiency term, and then calculate the Lerner index and cost efficiency with the new setting. The mean value of Lerner Index is 0.025 , very close to that estimated under the assumption of half-normal distribution. The mean value of cost efficiency is 0.965 , a little larger than that estimated with the half-normal distribution. Afterwards, we estimate the QLH model again with the Hausman-Taylor type IV and the assumption of exponential distribution of inefficiency term. The results are reported in column 3 of Table 6 . It suggests that the estimated coefficient of Lerner Index is still positive and statistically significant at the $1 \%$ level, verifying the robustness of our findings.

Third, firms with different scales may also behave and perform differently. To test the robustness of the results in terms of firm scale, the whole sample is partitioned into two subsamples according to the median of total assets of the firms investigated, and the 2SLS method is applied to estimate Model 7. As shown in columns 4 and 5 of Table 6 , the coefficients on the Lerner index in both subsamples are approximately

Table 6. Results of robustness check. ${ }^{1}$

\begin{tabular}{|c|c|c|c|c|c|}
\hline & $\begin{array}{l}\text { (1) } \\
\text { LIML }^{2}\end{array}$ & $\begin{array}{l}\text { (2) } \\
\text { GMM }^{2}\end{array}$ & $\begin{array}{l}\text { (3) } \\
\text { Exponential } \\
\text { distribution }\end{array}$ & $\begin{array}{l}\text { (4) } \\
\text { Smaller scale }\end{array}$ & $\begin{array}{l}\text { (5) } \\
\text { Larger scale }\end{array}$ \\
\hline \multirow[t]{2}{*}{ Lerner index } & $0.187^{* * *}$ & $0.203^{* * *}$ & $0.069^{* * *}$ & $0.218^{* * *}$ & $0.189^{* * *}$ \\
\hline & $(0.056)$ & $(0.050)$ & $(0.018)$ & $(0.061)$ & $(0.071)$ \\
\hline \multirow[t]{2}{*}{ Log (total asset) } & $0.002^{* *}$ & $0.003^{* * *}$ & -0.000 & $0.004^{* * *}$ & 0.001 \\
\hline & $(0.001)$ & $(0.001)$ & $(0.000)$ & $(0.002)$ & $(0.002)$ \\
\hline \multirow[t]{2}{*}{ Capital / output ratio } & -0.000 & $-0.001^{* * *}$ & $-0.001^{* * *}$ & -0.000 & $-0.002^{* *}$ \\
\hline & $(0.000)$ & $(0.000)$ & $(0.000)$ & $(0.000)$ & $(0.001)$ \\
\hline \multirow[t]{2}{*}{ Labour / output ratio } & 0.000 & 9.350 & 12.840 & -2.050 & 1.204 \\
\hline & $(0.003)$ & (12.690) & $(9.090)$ & (14.744) & $(74.631)$ \\
\hline Year fixed effect & no & no & no & no & no \\
\hline Year by firm effect & yes & yes & yes & yes & yes \\
\hline \multirow[t]{2}{*}{ Constant } & $0.932^{* * *}$ & $0.928^{* * *}$ & $0.970^{* * *}$ & $0.901^{* * *}$ & $0.962^{* * *}$ \\
\hline & $(0.017)$ & $(0.016)$ & $(0.004)$ & $(0.024)$ & $(0.030)$ \\
\hline Kleibergen-Paap rk LM statistic [ $P$-value] & & & $60.140[0.000]$ & $54.916[0.000]$ & $28.513[0.000]$ \\
\hline Kleibergen-Paap rk Wald F statistic & & & 64.923 & 65.551 & 33.210 \\
\hline Cragg-Donald Wald F statistic & & & 97.133 & 129.926 & 49.829 \\
\hline Obs. & 5,021 & 5,021 & 5,025 & 2,518 & 2,503 \\
\hline $\mathrm{R}^{2}$ & 0.221 & 0.220 & 0.166 & 0.213 & 0.230 \\
\hline
\end{tabular}


equal to 0.2 and statistically significant at the $1 \%$ level, which is in line with the whole sample. This result further proves the robustness of the findings. For the results of first-stage regressions of the above robustness check, see Supplementary Table S2.

Fourth, the 2008 global financial crisis generated large impacts on the international market, significantly affecting China, the largest emerging economy in the world. Many firms suddenly experienced falling demand and credit contraction. As shown in Table 2, the number of rice processing firms has been sharply decreasing since 2008. Therefore, there may be remarkable differences in the production and operations of firms before and after 2008. To test this view, the whole sample is partitioned into two subsamples taking 2008 as the separation year, and Model 7 is separately estimated using the 2SLS method. As shown in columns 1 and 2 of Table 7, the coefficients on the Lerner index are positive and statistically significant at the $1 \%$ level, which is in line with the results of the whole sample in terms of both sign and statistical significance. However, large differences exist in the magnitude of the coefficients between the two subsamples. The coefficient on the Lerner index is only 0.276 before 2008 , while it is 5.4 times larger after 2008 . This result implies that a slight enhancement of market power significantly improves the cost efficiency of China's rice processing firms after the 2008 global financial crisis. The reason may be that the financial crisis exacerbated competition in the industry, weeding out firms with low efficiency.

In addition, some studies have shown that a nonlinear relationship may exist between market power and cost efficiency (Färe et al., 2015); in other words, under different levels of competition, the effect of market power on cost efficiency may be different. To test this hypothesis, the whole sample is divided into two subsamples according to the median of the Lerner indices and estimated Model 7 separately. As shown in column 3 and 4 of Table 7, in the group with lower market power, the QLH is significantly rejected, while in the group with stronger market power, the effect of market power on cost efficiency is not statistically

Table 7. Results of heterogeneity analysis. ${ }^{1}$

\begin{tabular}{|c|c|c|c|c|c|c|}
\hline & $\begin{array}{l}(1) \\
1999- \\
2008\end{array}$ & $\begin{array}{l}(2) \\
2009- \\
2011\end{array}$ & $\begin{array}{l}\text { (3) } \\
\text { Weaker } \\
\text { MP }^{2}\end{array}$ & $\begin{array}{l}\text { (4) } \\
\text { Stronger } \\
\text { MP2 }^{2}\end{array}$ & $\begin{array}{l}\text { (5) } \\
\text { SOEs }\end{array}$ & $\begin{array}{l}(6) \\
\text { Non- } \\
\text { SOEs }\end{array}$ \\
\hline \multirow[t]{2}{*}{ Lerner index } & $0.276^{* * *}$ & $1.491^{* * *}$ & $0.283^{*}$ & 0.453 & -0.718 & $0.167^{* *}$ \\
\hline & $(0.051)$ & $(0.504)$ & $(0.167)$ & $(0.466)$ & $(0.455)$ & $(0.079)$ \\
\hline \multirow[t]{2}{*}{ Log (total asset) } & $0.003^{* * *}$ & $0.009^{* *}$ & $0.002^{*}$ & $0.002^{* *}$ & -0.010 & $0.002^{* *}$ \\
\hline & $(0.001)$ & $(0.004)$ & $(0.001)$ & $(0.001)$ & $(0.008)$ & $(0.001)$ \\
\hline \multirow[t]{2}{*}{ Capital / output ratio } & $-0.001^{* * *}$ & -0.007 & -0.003 & $-0.001^{*}$ & 0.004 & $-0.001^{* * *}$ \\
\hline & $(0.000)$ & $(0.004)$ & $(0.003)$ & $(0.0005)$ & $(0.007)$ & $(0.000)$ \\
\hline \multirow[t]{2}{*}{ Labour / output ratio } & 9.865 & $-2,489.20$ & -73.921 & 14.995 & -116.69 & $-345.9^{* * *}$ \\
\hline & (10.949) & $(915.96)$ & $(83.967)$ & $(11.363)$ & (191.74) & $(107.52)$ \\
\hline Year fixed effect & no & no & no & no & no & no \\
\hline Year by firm effect & yes & yes & yes & yes & yes & yes \\
\hline \multirow[t]{2}{*}{ Constant } & $0.914^{* * *}$ & $0.898^{* * *}$ & $0.938^{* * *}$ & $0.917^{* * *}$ & $1.117^{* * *}$ & $0.942^{* * *}$ \\
\hline & $(0.017)$ & $(0.075)$ & $(0.021)$ & $(0.031)$ & $(0.121)$ & $(0.020)$ \\
\hline \multirow[t]{2}{*}{ Kleibergen-Paap rk LM statistic [ $P$-value] } & 73.381 & 7.634 & 14.271 & 3.206 & 4.320 & 70.626 \\
\hline & {$[0.000]$} & {$[0.006]$} & {$[0.000]$} & {$[0.073]$} & {$[0.038]$} & {$[0.000]$} \\
\hline Kleibergen-Paap rk Wald F statistic & 83.309 & 7.888 & 14.190 & 3.185 & 4.177 & 85.581 \\
\hline Cragg-Donald Wald F statistic & 156.444 & 9.823 & 23.839 & 3.009 & 4.084 & 73.100 \\
\hline Obs. & 3,981 & 1,040 & 2,391 & 2,630 & 647 & 4,374 \\
\hline $\mathrm{R}^{2}$ & 0.099 & - & 0.267 & - & - & 0.233 \\
\hline
\end{tabular}


significant. The results suggest that from a policy point of view, more attention should be paid to firms with weaker market power. Preferential policies such as credit support may be applied to reduce the production and operation cost, thus raising the cost efficiency of those firms.

Finally, we devised a two-step process to make a comparison between state owned enterprises (SOEs) and non-stated owned enterprises (Non-SOEs). First, we partitioned the whole sample into two subsamples with different ownerships, and estimated the Lerner index and cost efficiency for SOEs and Non-SOEs separately. The results indicate that SOEs have significantly lower values for Lerner index and cost efficiency. Specifically, the mean values of Lerner index for SOEs and Non-SOEs are -0.008 and 0.030, respectively; of cost efficiency for SOEs and Non-SOEs 0.656 and 0.929, respectively. Second, we ran the IV regressions with these two subsamples separately. As shown in columns 5 and 6 of Table 7, the estimated coefficient of Lerner index for SOEs is negative and statistically insignificant, but that for Non-SOEs is 0.167 and statistically significant at the $5 \%$ level. These results, as expected, accord well with the findings of some previous studies that SOEs are found to be less cost-efficient than Non-SOEs (Ariff and Can, 2008; Fu and Heffernan, 2007). The firststage regression results of the heterogeneity analysis can be found in Supplementary Table S3.

\section{Discussion}

Based on the stochastic frontier cost function and firm-level panel data from 1999 to 2011, this study measures the market power and cost efficiency for China's rice processing firms and then investigates the effect of market power on cost efficiency. The 2SLS estimation results obtained using a Hausman-Taylor type IV indicate that market power has a significant and positive effect on the cost efficiency of rice processing firms in China, rejecting the QLH. The results are robust to the use of alternative estimation techniques. The study also finds heterogeneity in the empirical results in terms of periods and competition intensities. The magnitude of the positive effect of market power on cost efficiency is much larger after the 2008 global financial crisis. In addition, for less competitive firms, the QLH is significantly rejected, while for those that exhibit stronger market power, the effect of market power on cost efficiency is not statistically significant.

This study also has some limitations. First, it only focuses on the rice processing industry due to the difficulty in obtaining data. The main findings may not be necessarily tenable for other sectors. Second, it only discusses seller market power, and ignores buyer market power. The latter, as addressed by some previous studies, is also an important factor determining firms' efficiency. These issues will be resolved in future research.

\section{Supplementary material}

Supplementary material can be found online at: https://doi.org/10.22434/IFAMR2020.0119

Table S1. Results of first-stage regressions with the 2SLS method.

Table S2. Results of first-stage regressions of robustness check.

Table S3. Results of first-stage regressions of heterogeneity analysis.

\section{Disclosure statement}

There are no conflicts of interest to declare. This work was supported by [the Natural Science Foundation of China] under Grant [71803044]; [China's Humanities \& Social Sciences Research Project of Ministry of Education] under Grant [17YJC790139]; [Natural Science Foundation of Hunan Province] under Grant [2018JJ3358]; and [Social Science Foundation of Hunan Province] under Grant [17YBQ075].

\section{References}

Aigner, D., C.A.K. Lovell and P. Schmidt. 1977. Formulation and estimation of stochastic frontier production function models. Journal of Econometrics 6(1): 21-37. 
Al-Jarrah, I.M. and H. Gharaibeh. 2009. The efficiency cost of market power in the banking industry: a test of the 'Quiet Life' and related hypotheses in the Jordan banking industry. Investment Management and Financial Innovations 6(2): 32-39.

Al-Muharrami, S. and K. Methews. 2009. Market power versus efficient-structure in Arab GCC banking. Applied Financial Economics 19(18): 1487-1496.

Ariff, M. and L. Can. 2008. Cost and profit efficiency of Chinese banks: a non-parametric analysis. China Economic Review 19(2): 260-273.

Ariss, R.T. 2010. On the implications of market power in banking: evidence from developing countries. Journal of Banking \& Finance 34(4): 765-775.

Bauer, P.W., A.N. Berger, G.D. Ferrier and D.B. Humphrey. 2007. Consistency conditions for regulatory analysis of financial institutions: a comparison of frontier efficiency methods - techniques and applications. Journal of Economics \& Business 50(2): 85-114.

Berger, A.N. and T.H. Hannan. 1998. The efficiency cost of market power in the banking industry: a test of the 'Quiet Life' and related hypotheses. Review of Economics and Statistics 80: 454-465.

Brandt, L., J.V. Biesebroeck and Y. Zhang. 2012. Creative accounting or creative destruction? Firm-level productivity growth in Chinese manufacturing. Journal of Development Economics 97(2): 339-351.

Brandt, L., J.V. Biesebroeck, L. Wang and Y. Zhang. 2017. WTO accession and performance of Chinese manufacturing firms. American Economic Review 107(9): 2784-2820.

Casarin, A., M. Cornejo and M. Delfino. 2020. Market power absent merger review: brewing in Perú. Review of Industrial Organization 56: 535-556.

Casu, B. and C. Girardone. 2009. Testing the relationship between competition and efficiency in banking: a panel data analysis. Economics Letters 105(1): 134-137.

Chandy, R.K. and G.L. Tellis. 2000. The incumbent's curse: incumbency, size, and radical product innovation. Journal of Marketing 64: 1-17.

Che, Y. and L. Zhang. 2017. Human capital, technology adoption and firm performance: impacts of China's higher education expansion in the late 1990s. Economic Journal 4: 75-105.

Chen, X., D. Zeng, H. Zhang and C. Kang. 2020. Farm expansion under credit constraint: evidence from commercial rice farmers in Guangxi, China. International Food and Agribusiness Management Review 23(2): 203-215.

Chen, Y. and X. Yu. 2019. Do subsidies cause a less competitive milk market in China? Agricultural Economics 50(3): 303-314.

Claessens, S. and L. Laeven. 2004. What drives bank competition? Some international evidence. Journal of Money Credit \& Banking 36(3): 563-583.

Claessens, S. and L. Laeven. 2005. Financial dependence, banking sector competition, and economic growth. Journal of the European Economic Association 3(1): 179-207.

Coccorese, P. and A. Pellecchia. 2010. Testing the 'Quiet Life' hypothesis in the Italian banking industry. Economic Notes 39(3): 173-202.

Comanor, W.S. and H. Leibenstein. 1969. Allocative efficiency, X-efficiency and the measurement of welfare losses. Economica 36(143): 304-309.

Dai, J. and X. Li. 2020a. How does subsidy change a firm's market power? The case of China's rice processing industry. Journal of Applied Economics 23(1): 372-384.

Dai, J. and X. Li. 2020b. Market power, ownership and technical efficiency: an empirical test for China's food manufacturers. China Agricultural Economic Review 12(2): 275-294.

Delis, M.D. and E.G. Tsionas. 2009. The joint estimation of bank-level market power and efficiency. Journal of Banking \& Finance 33: 1842-1856.

Färe, R., S. Grosskopf, J. Maudos and E. Tortosaausina. 2015. Revisiting the quiet life hypothesis in banking using nonparametric techniques. Journal of Business Economics \& Management 16(1): 159-187.

Fu, X. and S. Heffernan. 2007. Cost X-efficiency in China's banking sector. China Economic Review 18(1): 35-53.

$\mathrm{Fu}, \mathrm{X}$. and S. Heffernan. 2009. The effects of reform on China's bank structure and performance. Journal of Banking and Finance 33(1): 39-52. 
Harding, M. and C. Lamarche. 2014. Estimating and testing a quantile regression model with interactive effects. Journal of Econometrics 178(P1): 101-113.

Hicks, J.R. 1935. Annual survey of economic theory: the theory of monopoly. Econometrica 3: 1-20.

Huang, T.H., N.H. Liu and S.C. Kumbhakar. 2018. Joint estimation of the Lerner index and cost efficiency using copula methods. Empirical Economics 54(2): 799-822.

Jondrow, J.M., D.E. Chase and C.L. Gamble. 1982. The price differential between domestic and imported steel. Journal of Business 55(3): 383-399.

Koetter, M. and O. Vins. 2008. The Quiet Life hypothesis in banking-evidence from German savings banks. Department of Finance, Goethe University, Working Paper Series: Finance and Accounting No. 190, Frankfurt, Germany.

Koetter, M., J.W. Kolari and L. Spierdijk. 2012. Enjoying the quiet life under deregulation? Evidence from adjusted Lerner indices for U.S. banks. The Review of Economics and Statistics 94(2): 462-480.

Kumbhakar, S.C. and C.A. Lovell. 2000. Stochastic frontier analysis. Cambridge University Press, New York, NY, USA.

Kumbhakar, S.C., H. Wang and A.P. Horncastle. 2015. A practitioner's guide to stochastic frontier analysis using STATA. Cambridge University Press, New York, NY, USA.

Kutlu, L. and R.C. Sickles. 2012. Estimation of market power in the presence of firm level inefficiencies. Journal of Econometrics 168: 141-155.

Leibenstein, H. 1966. Allocative efficiency vs. 'X-efficiency'. The American Economic Review 56(3): 392-415.

Lerner, A.P. 1934. The concept of monopoly and the measurement of monopoly power. The Review of Economic Studies 1: 157-175.

Liu, Z. 2018. China Food Industry Yearbook 2017. China Statistics Press, Beijing, China.

Liu, T. 2019. Effect of factor endowment structure change on cost efficiency of grain production: based on the data of major rice-producing provinces between 2004 and 2016. Journal of Hunan Agricultural University (Social Sciences) 20(1): 18-25.

Maudos, J. and F.D. Guevara J. 2007. The cost of market power in banking social welfare loss vs. cost efficiency. Journal of Banking and Finance 31(7): 2103-2125.

Meeusen, W. and J.V.D. Broeck. 1977. Technical efficiency and dimension of the firm: some results on the use of frontier production functions. Empirical Economics 2(2): 109-122.

National Bureau of Statistics of China. 2012. China Statistical Yearbook 2000-2012. China Statistics Press, Beijing, China.

Pruteanu-Podpiera, A., L. Weill and F. Schobert. 2008. Banking competition and efficiency: a micro-data analysis on the Czech banking industry. Comparative Economics Studies 50(2): 253-273.

Raper, K.C., H.A. Love and C.R. Shumway. 2007. Distinguishing the source of market power. American Journal of Agricultural Economics 89(1): 78-90.

Schaeck, K. and M. Cihak. 2008. How does competition affect efficiency and soundness in banking? New empirical evidence. ECB Working Paper Series No. 932, European Central Bank, Frankfurt, Germany.

Schmidt, P. and K.C. Lovell. 1979. Estimating technical and allocative inefficiency relative to stochastic production and cost frontiers. Journal of Econometrics 9(3): 343-366.

Shepherd, W.G. 1972. Market power and economic welfare: an introduction. Random House, New York, NY, USA.

Solís, L. and J. Maudos. 2008. The social costs of bank market power: evidence from Mexico. Journal of Comparative Economics 36(3): 469-488.

Tetsushi, H., T. Yoshiro and U. Hirofumi. 2012. Firm growth and efficiency in the banking industry: a new test of the efficient structure hypothesis. RIETI Discussion Paper Series 12-E-060, RIETI, Tokyo, Japan.

Tu, A.H. and S. Chen. 2000. Bank market structure and performance in Taiwan before and after the 1991 liberalization. Review of Pacific Basin Financial Markets and Policies 3(4): 475-490.

Vives, X. 2020. Common ownership, market power, and innovation. International Journal of Industrial Organization 70: 1-12.

Wang, J., W. Zhang and P. Xue. 2019. Technical efficiency, financial constraints and enterprise expansion: an investigation and analysis based on 150 rice processing firms. Journal of Agrotechnical Economics 6: 120-131. 
Yu, S., T. Liu and B. Cao. 2019. Effects of agricultural mechanization service on the cost efficiency of grain production. Journal of Huazhong Agricultural University (Social Sciences Edition) 4: 81-89. (in Chinese) 
